\title{
FUNÇÃO SOCIAL DA PROPRIEDADE: A CONSTITUIÇÃO ECONÔMICA O DESENVOLVIMENTO SUSTENTÁVEL
}

\author{
SOCIAL FUNCTION OF PROPERTY: THE ECONOMIC CONSTITUTION AND
}

SUSTAINABLE DEVELOPMENT

Thiago Lemos Possas*

Elisabete Maniglia**

\section{Resumo}

O presente trabalho versa sobre a função social da propriedade, sua localização na Constituição Econômica presente na Constituição da República de 1988, bem como sua relação com o conceito de sustentabilidade, muito em voga hodiernamente. Busca-se, ainda, tratar a função social de forma crítica, através da abordagem de suas limitações intrínsecas, bem como da falta de compreensão e recepção por parte do mundo jurídicoinstitucional. E o enfoque a ser dado, cabe enfatizar, é eminentemente o da função social da propriedade agrária. Almeja-se ressaltar, por fim, que a correta consideração da função social da propriedade poderá converter-se em um primeiro passo para a configuração de uma sociedade mais harmônica, solidária e includente.

Palavras-chave: Função Social da Propriedade; Constituição Econômica; Sustentabilidade.

\begin{abstract}
The present work deals with the social function of property, its location in the Constitution in this Economic Constitution of 1988, as well as its relationship with the concept of sustainability, much in vogue in our times. The aim is to also address the social function critically, by addressing its inherent limitations, as well as the lack of understanding and received by the legal and institutional world. And the focus to be given, it should be emphasized, is eminently the social function of the agrarian property. It is longed to be noted, finally, that the proper consideration of the social function of property can become a first step in setting a more harmonious society, caring and inclusive.
\end{abstract}

Keywords: Social Function of Property; Economic Constitution; Sustainability.

\section{Introdução}

\footnotetext{
* Possui graduação em Direito pela Universidade Federal de Minas Gerais (2008). Especialização em Direito Público pela UNIDERP/LFG. Mestrado em Direito Público pela UNESP. Doutorando em Direito pela USP.

Possui graduação em Comunicação Social Jornalismo pela Universidade de São Paulo (1975), graduação em Direito pela Universidade Estadual Paulista Júlio de Mesquita Filho (1988), mestrado em Direito pela Universidade de São Paulo (1994) e doutorado em Direito pela Universidade Estadual Paulista Júlio de Mesquita Filho (2000).Defendeu livre docência em 2007 e atualmente é professora adjunto da Universidade Estadual Paulista Júlio de Mesquita Filho. Tem experiência na área de Direito, com ênfase em Direito Agrário e ambiental rural, atuando principalmente nos seguintes temas: reforma agrária, direito agrário, trabalho rural, direito empresarial rural e direitos humanos.Sua área de pesquisa esta voltada neste momento para produção agrária, segurança alimentar e políticas públicas de sustentabilidade rural. Membro da Comissão de Direito Agrário, da Rede Nacional de Advogados Populares (RENAP), Ordem dos Advogados do Brasil, Associação Brasileira de Reforma Agrária (ABRA), Associação Brasileira de Direito Agrário (ABDA).
} 
Muito já se tratou do princípio (hoje já vetusto) da Função Social da Propriedade, o que leva a indagar sobre a pertinência e tempestividade do assunto enfocado. É de clareza meridiana a necessidade de se impor limites jurídicos à propriedade privada, ainda mais quando cotejados os contingentes proprietário e nãoproprietário.

Mas, infelizmente, o antigo instituto ainda não logrou a aceitação geral e observância nem mesmo pelos militantes do Direito que, em tese, deveriam atuar em conformidade com a Constituição (que o consagrou expressamente). Cabe lembrar, neste ponto, que a função social não surgiu no ordenamento jurídico pátrio em 1988, já constando no Estatuto da Terra (1964), sendo o art. 186 da Constituição quase uma repetição do constante na legislação anterior, mas com a importante diferença de consignar em primeiro plano a questão da produtividade (MANIGLIA: 2005; 29), proporcionando, como se verá mais adiante, interpretações muitas vezes desconectadas de uma análise sistêmica do texto constitucional.

Jean-Jacques Rousseau ${ }^{1}(2007$; 39) no século XVIII já se manifestava pela exigência de que a propriedade cumprisse uma função social como condição de autorização do direito de seu primeiro ocupante:

Em geral, para autorizar num pedaço de terra qualquer o direito de primeiro ocupante, são requeridas as seguintes condições. Primeiro, que esse terreno não seja ainda habitado por ninguém; segundo, que se ocupe apenas a quantidade necessária para a subsistência; terceiro, que se tome posse não por uma vã cerimônia, mas pelo trabalho e pelo cultivo, único sinal de propriedade que, na falta de títulos jurídicos, deve ser respeitado por outrem.

Séculos se passaram e a questão ainda é premente e controversa no Brasil, país que tem o "patrimonialismo" fortemente arraigado no ideário das elites, acompanhado de uma concentração fundiária inaceitável, que convive com a fome do outro lado da cerca.

O presente trabalho almeja tratar do princípio da função social, sua localização na chamada Constituição Econômica, e a sua relação com o conceito de sustentabilidade, em voga. 
Além disso, pretende abordar a função social de forma crítica, elencando algumas de suas limitações essenciais, bem como a falta de compreensão e recepção por parte do mundo jurídico-institucional.

E o enfoque a ser dado, cabe enfatizar, é eminentemente o da função social da terra, ou melhor, da propriedade agrária ${ }^{2}$.

\section{Direito de Propriedade: a origem liberal e o constitucionalismo democrático brasileiro}

\subsection{Origens do Direito de Propriedade}

Nas Revoluções Burguesas situa-se o nascedouro do constitucionalismo e dos elementos norteadores do conteúdo dos direitos fundamentais:

Em rigor, o lema revolucionário do século XVIII, esculpido pelo gênio político francês, exprimiu em três princípios cardeais todo o conteúdo possível dos direitos fundamentais, profetizando até mesmo a seqüência histórica de sua gradativa institucionalização: liberdade, igualdade e fraternidade (BONAVIDES: 2009; 562).

Para Bonavides, neste primeiro momento, viu-se a emergência dos direitos de primeira geração, tendo como titular o indivíduo, e oponíveis ao Estado, sendo direitos de resistência, ostentadores da subjetividade como traço característico, correspondendo a uma visão política de separação entre a sociedade e o Estado (BONAVIDES: 2009; 563-564).

Com relação a estes direitos, vale ressaltar que: "São por igual direitos que valorizam primeiro o homem-singular, o homem das liberdades abstratas, o homem da sociedade mecanicista que compõe a chamada sociedade civil, da linguagem jurídica mais usual" (BONAVIDES: 2009; 564).

Consoante advertência de José Luiz Quadros de Magalhães (2008; 18), os mencionados direitos eram restritos a um grupo seleto de homens proprietários, sendo que a grande maioria da população "permanecia fora do novo sistema de garantia de 
direitos", destacando, também, o fato de que o "constitucionalismo não nasceu democrático, e o lento processo de democratização, em uma tensão permanente até os dias de hoje, ocorreu devido às lutas dos movimentos operários e dos partidos políticos de esquerda que se formaram no século XIX".

Neste contexto, o direito de propriedade, "absoluto e intocável", é concebido como a base do Estado Liberal, sendo a propriedade privada a base da própria liberdade (MAGALHÃES: 2008; 19 e 82).

Erigiu-se, então, a propriedade privada como centro do novo paradigma em formação. Contra este acontecimento, bradou Jean-Jacques Rousseau (2005; 61):

O primeiro que tendo cercado um terreno se lembrou de dizer: Isto é meu, e encontrou pessoas bastantes simples para o acreditar, foi o verdadeiro fundador da sociedade civil. Quantos crimes, guerras, assassínios, misérias e horrores não teria poupado ao gênero humano aquele que, arrancando as estacas ou tapando os buracos, tivesse gritado aos seus semelhantes: "Livrai-vos de escutar esse impostor; estareis perdidos se esquecerdes que os frutos são de todos, e a terra de ninguém".

Coube ao capitalismo a transfiguração da terra em objeto do direito de propriedade (séc. XVIII), direito este que se constituiu em "essência" da civilização, agredindo a natureza e minando a fraternidade, transformando a propriedade em bem jurídico com valor de troca (MARÉS: 2003; 14, 23, 26). E o Direito veio a agasalhá-la com um manto quase inquebrantável.

Ocorre que a própria lógica burguesa de defesa do direito de propriedade continha o gérmen da contestação social dos que não tinham acesso a este direito: "A lógica do raciocínio tornou incoercível o movimento político reivindicatório”, e, assim, “o acesso à propriedade adquiria pois, insofismavelmente, o caráter de direito fundamental da pessoa humana" (COMPARATO, 2000).

A Constituição brasileira de 1988 consagrou (no plano constitucional, vale dizer, já que o instituto já havia sido objeto de legislação anterior, o Estatuto da Terra) o novo status do direito de propriedade, desconectando-o do paradigma liberal.

\subsection{A Constituição de 1988 e o Direito de Propriedade}


Hodiernamente, o Direito, em seu ramo privado, sofreu considerável "relativização" em razão de sua função social (BERCOVICI: 2005; 142-143), sendo que "os direitos individuais não devem mais ser entendidos como pertencentes ao indivíduo em seu exclusivo interesse, mas como instrumentos para a construção de algo coletivo". Verificou-se, historicamente, o processo de "funcionalização" da propriedade, (BERCOVICI: 2005; 145): "O processo de funcionalização da propriedade foi demonstrado por Karl Renner, que analisou como a função social da propriedade se modifica com as mudanças nas relações produtivas, transformando a propriedade capitalista, sem socializá-la”. A função social, destarte, operou uma mudança essencial no capitalismo, na medida em que passou a fundamentar juridicamente a propriedade (BERCOVICI: 2005; 145).

Consoante a doutrina de Eros Roberto Grau (2008; 247): “o princípio da função social da propriedade, desta sorte, passa a integrar o conceito jurídico-positivo de propriedade (...), de modo a determinar profundas alterações estruturais na sua interioridade". E, prossegue o jurista: "em razão disso - pontualizo - é que justamente a sua função justifica e legitima essa propriedade".

A Constituição da República de 1988 confirma o entendimento acima, na medida em que assegura o direito à propriedade, mas o liga visceralmente à função social, sem a qual estará o Estado autorizado a iniciar o processo desapropriatório.

E, neste caso, não há que falar em direito humano à propriedade, quando esta se converte em instrumento de opressão/exclusão, conforme as lições de Fábio Konder Comparato:

Escusa insistir no fato de que os direitos fundamentais protegem a dignidade da pessoa humana e representam a contraposição da justiça ao poder, em qualquer de suas espécies. Quando a propriedade não se apresenta, concretamente, como uma garantia da liberdade humana, mas, bem ao contrário, serve de instrumento ao exercício de poder sobre outrem, seria rematado absurdo que se lhe reconhecesse o estatuto de direito humano, com todas as garantias inerentes a essa condição, notadamente a de uma indenização reforçada na hipótese de desapropriação. 
Fazendo uma breve exegese constitucional, temos o art. $5^{\circ}$, inciso XXII, a garantir expressamente o direito de propriedade e, no inciso subsequente, determinar que "a propriedade atenderá a sua função social". O inciso XXIV, do art. $5^{\circ}$, consigna que "a lei estabelecerá o procedimento para desapropriação por necessidade ou utilidade pública, ou por interesse social, mediante justa e prévia indenização em dinheiro, ressalvados os casos previstos nesta Constituição".

Mais adiante, no Título VII do texto constitucional, "Da ordem econômica e financeira", logo no Capítulo I, "Dos princípios gerais da atividade econômica", tem-se a função social da propriedade a figurar entre os princípios da ordem econômica (art. 170, III). No Capítulo III do mesmo Título encontra-se o regramento constitucional pertinente à Reforma Agrária.

Conforme determina o art. 184 da $\mathrm{CF} / 88$ :

Compete à União desapropriar por interesse social, para fins de reforma agrária, o imóvel rural que não esteja cumprindo sua função social, mediante prévia e justa indenização em títulos da dívida agrária, com cláusula de preservação do valor real, resgatáveis no prazo de até vinte anos, a partir do segundo ano de sua emissão, e cuja utilização será definida em lei.

O art. 186, inserto no mesmo Capítulo da Constituição, tratou especificamente da função social da propriedade rural, em sua diversidade de elementos ${ }^{3}$.

A função social foi expressamente estabelecida como inerente (ou pressuposto) ao direito de propriedade, como princípio constitucional da ordem econômica, bem como, mais especificamente no âmbito rural, "fundamento básico da reforma agrária" (BERCOVICI: 2005; 152). Como visto, ela compreende diversas facetas: a racionalidade no aproveitamento da terra, a preocupação com o elemento ambiental, com os direitos trabalhistas e com o bem-estar tanto dos proprietários quanto dos que nela labutam.

Este caráter multifacetário do instituto denota sua intrínseca relação com o conceito de sustentabilidade, que ganha relevo nos debates contemporâneos sobre 
desenvolvimento, e que parece estar em íntima relação não apenas com a função social da propriedade, mas com alguns princípios da Constituição Econômica.

Passa-se, a seguir, a tratar da relação entre a função social e o Direito Econômico para, posteriormente, definir o conceito de sustentabilidade, relacionando-o com a temática abordada.

\subsubsection{A Função Social e o Direito Econômico}

Portanto, merecedor de destaque é a inscrição da função social da propriedade na parte do texto constitucional relativa à chamada "Constituição Econômica".

Desde o século XX, as Constituições não recebem mais passivamente uma estrutura econômica prévia, mas almejam alterá-la (BERCOVICI: 2005; 33): "Elas positivam tarefas e políticas a serem realizadas no domínio econômico e social para atingir certos objetivos. A ordem econômica destas Constituições é 'programática' hoje diríamos "dirigente"” (Idem). Segundo o citado autor, as Constituições Econômicas do século XX são essencialmente diretivas, ou dirigentes. Elas tornam "mais clara a ligação da Constituição com a política e com as estruturas sociais e econômicas" (Idem).

A correlação entre política, Constituição e as estruturas sócio-econômicas implica na alteração destas através da atuação política fundamentada na Constituição. E, neste ponto, a Constituição brasileira apresenta um arcabouço normativo razoável para a alteração estrutural da sociedade.

A Constituição brasileira conferiu à função social da propriedade status de Direito Econômico Fundamental (MAGALHÃES: 2008; 250), além da relação intrínseca com o conceito de propriedade privada atual. Este fato tem (ou deveria ter) fortes consequências na estruturação da sociedade. A consagração do instituto como um Direito Econômico lhe confere relevante potencial transformador. 
Para elucidar a argumentação, José Luiz Quadros de Magalhães (2008; 240), acerca do Direito Econômico, entende que:

Esse ramo do Direito regulamenta juridicamente a política econômica que deve estar sujeita à ideologia constitucionalmente adotada; portanto, em uma Constituição que, como a de 1988, estabelece como princípios fundamentais o respeito à dignidade humana, a erradicação da pobreza, a redução das desigualdades sociais e regionais, a prevalência dos direitos humanos, o Direito Econômico se transforma em importante e fundamental mecanismo de transformação da realidade econômica e social, através de uma política econômica adequada aos princípios constitucionais citados.

Os princípios fundamentais supracitados se encontram no Título I da Carta Magna. Neste Título, o art. $3^{\circ}$ elenca os objetivos fundamentais da República: I construir uma sociedade livre, justa e solidária; II - garantir o desenvolvimento nacional; III - erradicar a pobreza e a marginalização e reduzir as desigualdades sociais e regionais; IV - promover o bem de todos, sem preconceitos de origem, raça, sexo, cor, idade e quaisquer outras formas de discriminação.

Este artigo é tido como a "cláusula transformadora" da Constituição, na expressão do jurista Pablo Lucas Verdú, a qual explicita a realidade social injusta e a necessidade de transformá-la (BERCOVICI: 2005; 36). Os princípios elencados no art. $3^{\text {o }}$ denotam escolhas "ideológicas essenciais sobre as finalidades sociais e econômicas do Estado, cuja realização é obrigatória para os órgãos e agentes estatais e para a sociedade ou, ao menos, os detentores de poder econômico ou social fora da esfera estatal" (Idem; 110).

Portanto, o dispositivo citado estabelece um "programa de atuação para o Estado e a sociedade brasileiros, determinando o sentido e o conteúdo de políticas públicas que, se implementadas, consubstanciariam uma real ruptura com as atuais estruturas sociais e econômicas" (Idem; 113).

Além da "cláusula transformadora" inscrita no art. 3º próprio Título relativo à Ordem Econômica e Financeira traz relevantes dispositivos que, se levados em conta na interpretação constitucional, poderão se converter em importantes instrumentos de concretização de direitos fundamentais e alteração do status quo injusto. 
Desta forma, imperioso concluir que a função social da propriedade deverá, por expressa previsão constitucional, ser considerada um dos pilares da ordem econômica, devendo o Estado levá-la em conta em toda a sua atuação no plano econômico. Toda a política econômica ${ }^{4}$ promovida pelo Estado brasileiro, portanto, deverá ter como base a função social da propriedade, entre outras coisas, com vistas a "assegurar a todos existência digna, conforme os ditames da justiça social" (Constituição Federal, art. 170, caput).

Sobre a inserção do "princípio da garantia da propriedade privada dos bens de produção entre os princípios da ordem econômica”, entende Eros Roberto Grau (2008; 248) que isso implica não apenas na sua afetação pela função social, mas ainda por "subordinar o exercício dessa propriedade aos ditames da justiça social e de transformar esse mesmo exercício em instrumento para a realização do fim de assegurar a todos existência digna".

A inserção do instituto junto à Constituição Econômica aponta na direção de um desenvolvimento norteado por valores outros que não os de um crescimento irresponsável e excludente, que mantém a estrutura social injusta, e é indiferente à questão ambiental.

E é aqui que ganha importância a correlação entre alguns princípios da Constituição Econômica e o conceito de sustentabilidade, figurando a função social como ponto fundamental desta confluência.

\subsubsection{A Função Social da Propriedade e a "Sustentabilidade"}

Esta concepção de função social da propriedade, fundamentada em seus elementos constitucionalmente consagrados, parece conectar-se com as atuais concepções de "desenvolvimento sustentável" que se estrutura em "três pilares", a saber, "atender simultaneamente os critérios de relevância social, prudência ecológica e viabilidade econômica" (SACHS: 2009; 35). 
Sobre o debate acerca da ideia de desenvolvimento sustentável, observa Ignacy Sachs $(2009 ; 52)$ que surgiu uma "alternativa média" entre o "economicismo arrogante e o fundamentalismo ecológico", que não deixou de considerar a necessidade de crescimento econômico, mas que, com relação a este, mostrou a necessidade de "ser socialmente receptivo e implementado por métodos favoráveis ao meio ambiente, em vez de favorecer a incorporação predatória do capital da natureza ao PIB”. E, para a concretização desta empreitada "uma distribuição diferente da propriedade e renda era certamente necessária” (Idem).

Mais adiante, o autor (Idem; 60) destaca a reconceitualização do “desenvolvimento como apropriação efetiva de todos os direitos humanos, políticos, sociais, econômicos e culturais, incluindo-se aí o direito coletivo ao meio ambiente". É relevante realçar esta concepção para que não se perca de vista que "sustentabilidade" não diz respeito apenas à questão ambiental, sendo esta apenas um aspecto do conceito. Não há que se cogitar a primazia da "sustentabilidade ambiental" em detrimento da social. A primazia e a razão de ser da sustentabilidade é o aspecto social, sempre.

É esclarecedora, neste sentido, a doutrina do próprio Sachs (2009; 71-72): "Muitas vezes o termo [sustentabilidade] é usado para expressar a sustentabilidade ambiental. Creio, no entanto, que este conceito tem diversas outras dimensões". E prossegue: "a sustentabilidade social vem na frente, por se destacar como a própria finalidade do desenvolvimento, sem contar com a probabilidade de que um colapso social ocorra antes da catástrofe ambiental; (...) a sustentabilidade do meio ambiente vem em decorrência;”. A centralidade de seu argumento $(2009 ; 66)$ reside na concepção de desenvolvimento como "processo histórico de apropriação universal pelos povos da totalidade dos direitos humano, individuais e coletivos, negativos (liberdade contra) e positivos (liberdade a favor)".

Neste sentido, como visto, parece ser impensável uma "sustentabilidade" que confira proeminência à questão ambiental em detrimento da "questão social", esta sim primacial para o desenvolvimento humano.

\section{Limites do princípio da Função Social da Propriedade}


É evidente que o "descumprimento da função social é um ataque às reservas naturais, aos direitos humanos, aos direitos sociais, à economia nacional, ao desenvolvimento, à 'segurança alimentar', enfim, a um grande número de interesses da sociedade em geral" (MELO: 2009; 88).

A relevância do instituto para as finalidades de concretização de direitos fundamentais, de transformação da sociedade, de direcionamento da política econômica, é incontestável. A articulação entre a Constituição Econômica e a ideia de sustentabilidade, desde que bem compreendida, apresenta-se como salutar na alteração do status quo injusto com o povo e agressor do meio ambiente.

Mas, a função social esbarra em alguns limites que transcendem a questão jurídico-constitucional. E, talvez, possa se apontar, também, uma limitação intrínseca ao instituto para os fins a que foi consagrado.

Por exemplo, a sua relevância foi largamente demonstrada nos dispositivos constitucionais citados, onde aparece nominalmente, bem como em sua ligação com os princípios fundamentais da República, "com respeito à dignidade humana, visando erradicar a pobreza e diminuir as desigualdades", mas o que ocorre é que "todo esse complexo se vê reduzido à aferição de índices de produtividade" (MELO: 2009; 99), em redução inaceitável do instituto, no que se refere à propriedade rural.

Há um completo esvaziamento da função social reduzida à medição de índices de produtividade insuficientes para determinação de seu cumprimento em toda a sua complexidade. A questão ambiental, trabalhista, a consideração do bem-estar de trabalhadores e proprietários, são completamente negligenciadas, em conduta afrontosa à Constituição por parte de agentes públicos cuja incumbência seria a de, justamente, averiguar o cumprimento dos dispositivos constitucionais pertinentes à propriedade.

O INCRA, instituição competente para a fiscalização do cumprimento da função social da propriedade rural, deveria aferir corretamente o cumprimento da mesma e, em caso negativo, atestar a inadequação em seus laudos para que o procedimento desapropriatório tivesse início. Mas o que ocorre, na realidade, é que nas vistorias os laudos acabam sendo emitidos com fulcro apenas na produtividade, através 
da medição dos índices de GDU (graus de utilização da terra, que deve totalizar até 80\% das terras economicamente aproveitáveis) e o GDE (grau de eficiência, que deverá ser igual ou superior a 100\%), ficando a análise, destarte, circunscrita à aferição do fator econômico, em detrimento dos demais (MANIGLIA: 2005; 37).

Outro problema grave é a não recepção da mudança no conceito de propriedade e na consequente mudança no tratamento a ela conferido no texto constitucional. $\mathrm{O}$ menosprezo à Constituição se dá, neste ponto, pelos que deveriam defendê-la. Os militantes do Direito parecem ainda não ter recepcionado devidamente a substancial mudança paradigmática no que tange à dimensão social conferida ao (outrora absoluto) direito de propriedade.

Destarte, segundo Tarso de Melo (2009; 61), “a propriedade, enquanto instituto histórico, é ainda hoje o mais sagrado dos institutos, e sua sacralidade implica dogmaticidade, no sentido de que não se deve questioná-lo”. Parte considerável do Poder Público parece não ter se dado conta da substancial alteração do conteúdo da propriedade, nos moldes do constitucionalismo democrático.

O Executivo claramente não observa o princípio, pois não empreendeu, ainda, uma reforma agrária ampla e complexa, como manda a Constituição. E o Judiciário, por sua vez, parece ainda excessivamente arraigado ao já ultrapassado paradigma liberal, com notória incapacidade para visualizar o Direito de um ponto de vista coletivo, social, mantendo-se atados aos direitos individuais isoladamente, em patente violação constitucional. É o que diagnosticou Lênio Luiz Streck (2005; 278), em instigante obra: "os juristas, de forma inautêntica, (ainda) interpretam o texto constitucional com pré-juizos advindos/originários de um campo jurídico próprio do modelo de Direito forjado no paradigma liberal-individualista-normativista de Direito".

O problema de efetividade do direito de propriedade em seus novos moldes, com a observância de sua função social (e não mais meramente individual), passa, também, por esta inadequação entre a interpretação operada por parte do Judiciário, ancorada em anacronismos, e o texto constitucional que levou a cabo uma alteração substancial no conceito de propriedade. 
A alteração desta situação passa também, portanto, pelo trabalho nas faculdades de Direito em prol da conscientização social, e do estudo crítico e reflexivo, para a formação de novos juristas preocupados com "o Direito que faz Justiça", para que a sociedade não mais sofra diante do desemprego, da fome e dos danos ambientais (MANIGLIA: 2005; 31 e 42).

Lado outro, o próprio instituto possui limitações intrínsecas, na medida em que permite a manutenção de uma estrutura fundiária desigual, excludente, já que o cumprimento da função social é suficiente para legitimar (de um ponto de vista normativo) a manutenção de grandes propriedades, mesmo convivendo com a luta pela sobrevivência de milhões de famílias que não possuem terra.

Vale lembrar, ainda, que o princípio da função social da propriedade serve para "instrumentalizar a implementação de uma aspiração autenticamente capitalista: a de preservação da propriedade privada dos bens de produção - à função social está assujeitada porque é privada" (GRAU: 2008; 248). Ou seja, nada mais equivocado que proclamar o princípio como tendo viés socialista.

Em 2010 houve um Plebiscito popular que visava, entre outras coisas, "demonstrar ao Congresso Nacional que o povo brasileiro deseja que se inclua na Constituição um novo inciso limitando a propriedade da terra - princípio adotado por vários países capitalistas - a 35 módulos fiscais.” (BETTO, 2010).

A despeito do imenso simbolismo deste ato cívico, e da participação efetiva de segmentos sociais, parece que não houve sensibilização do Congresso, até o momento, para a questão. A divisão absurdamente desigual da propriedade da terra vigora (quase) intangível.

Vê-se bem que, mesmo com uma correta observância e aplicação do instituto, há limites evidentes na própria função social da propriedade. Ocorre que, conforme demonstrado, seus limites vão além do próprio instituto, fazendo parte do "senso comum teórico dos juristas", na expressão de Luis Alberto Warat, o que redunda em sua inefetividade. 


\section{Apontamentos Finais}

Buscou-se demonstrar no presente trabalho os limites e o alcance do princípio da função social da propriedade, enquanto elemento essencial do direito de propriedade repaginado pela Constituição da República de 1988, no Brasil.

A despeito das patentes limitações, a função social carrega considerável potencialidade de mudança estrutural na sociedade brasileira, desde que corretamente observada.

Vislumbra-se, paralelamente, uma aproximação entre a Constituição Econômica e o conceito de sustentabilidade, figurando a função social como elemento central desta relação. É através da observância do princípio que se poderá trilhar um caminho de efetivo desenvolvimento que não descuida de sua multiplicidade de facetas: a humana, a social, a ambiental, a política, a geográfica.

Para tanto, o item produtividade deve ser cotejado com a função social de garantia da segurança alimentar, mormente se considerada a realidade nacional onde, por absurdo que pareça, ainda há fome e pobreza extrema. A questão ambiental deve ser aprimorada cotidianamente com a conscientização da sociedade, com a finalidade de se exigir produtos de boa qualidade, com preços acessíveis, e a exploração das reservas e áreas de preservação ambiental em consonância com o ideal de sustentabilidade. O item pertinente ao social deve ser repensado, enfatizando-se a construção de uma democracia participativa substancial, e a atuação do Estado por meio de políticas públicas eficientes (MANIGLIA: 2005; 42-43).

Assim, a correta consideração da função social da propriedade poderá se converter em um primeiro passo para a configuração de uma sociedade mais harmônica, solidária, includente, favorecendo a construção de novos valores contrários aos que imperam atualmente, e que já causaram tanta injustiça.

Mas, que fique claro: é apenas o primeiro passo. Serão necessários muitos outros para a realização de uma sociedade substancialmente democrática. 
Caso este passo não seja dado, continuará a vigorar o triste quadro denunciado no longínquo século XVIII por Rousseau (2005; 88), e que não perdeu a atualidade, onde um "punhado" de pessoas nada no supérfluo, "enquanto à multidão esfomeada falta o necessário".

\section{Referências Bibliográficas}

BERCOVICI, Gilberto. Constituição Econômica e Desenvolvimento: uma leitura a partir da Constituição de 1988. São Paulo: Malheiros, 2005.

BETTO, Frei. Plebiscito pelo Limite da Terra. Disponível em <www.limitedaterra.org.br>. Acesso em: 28 de agosto de 2010.

BONAVIDES, Paulo. Curso de Direito Constitucional. São Paulo: Malheiros, 2009.

COMPARATO, Fábio Konder. "Direitos e Deveres Fundamentais em Matéria de Propriedade”. A questão agrária e a justiça. Juvelino José Strozake (org.). São Paulo: RT, 2000.

GRAU, Eros Roberto. A Ordem Econômica na Constituição de 1988. 13ª ed. São Paulo: Malheiros, 2008.

MAGALHÃES, José Luiz Quadros de. Direito Constitucional - Curso de Direitos Fundamentais. $3^{\mathrm{a}}$ ed. São Paulo: Método, 2008.

MANIGLIA, Elisabete. Atendimento da Função Social pelo Imóvel Rural. In: BARROSO, Lucas de Abreu; MIRANDA, Alcir Gusten de; SOARES, Mário Lúcio Quintão. O Direito Agrário na Constituição. Rio de Janeiro: Forense, 2005.

MARÉS, Carlos Frederico. A Função Social da Terra. Porto Alegre: Sérgio Antônio Fabris Editor, 2003.

MELO, Tarso de. Direito e Ideologia: um estudo a partir da função social da propriedade rural. São Paulo: Expressão Popular, 2009.

ROUSSEAU, Jean-Jacques. Discurso sobre a Origem e os Fundamentos da Desigualdade entre os Homens. São Paulo: Martin Claret, 2005. O Contrato Social. Porto Alegre: LP\&M, 2007.

SACHS, Ignacy. Caminhos para o desenvolvimento sustentável. Rio de Janeiro: Garamond, 2009.

STRECK, Lênio Luiz. Hermenêutica Jurídica e $(m)$ Crise. $6^{\text {a }}$ ed. Porto Alegre: Livraria do Advogado, 2005. 


\footnotetext{
${ }^{1}$ Sobre a ambigüidade da posição do pensador genebrino frente ao direito de propriedade, vide o texto de autoria de Fábio Konder Comparato, citado nas Referências Bibliográficas.

${ }^{2}$ Sobre a evolução do conceito de "terra" a "propriedade", vide o livro de Carlos Frederico Marés (2003).

3 “A função social é cumprida quando a propriedade rural atende, simultaneamente, segundo critérios e graus de exigência estabelecidos em lei, aos seguintes requisitos: I - aproveitamento racional e adequado; II - utilização adequada dos recursos naturais disponíveis e preservação do meio ambiente; III observância das disposições que regulam as relações de trabalho; IV - exploração que favoreça o bemestar dos proprietários e dos trabalhadores".
}

${ }^{4}$ Segundo Bercovici (2005; 13), seria justamente a partir da "presença do econômico no texto constitucional e da ideologia constitucionalmente adotada que se elaboraria a política econômica do Estado". Nesta linha, ganha relevo a função social como essencial à política econômica. 